\title{
ENHANCED GaN DECOMPOSITION AT MOVPE PRESSURES
}

D.D. KOLESKE, A.E. WICKENDEN, R.L. HENRY, M.E. TWIGG, J.C. CULBERTSON, AND R.J. GORMAN, Code 6800, Electronic Science and Technology Division, Naval Research Laboratory, Washington, D.C. 20375

\section{Cite this article as: MRS Internet J. Nitride Semicond. Res. 4S1, G3.70 (1999)}

\section{ABSTRACT}

GaN decomposition was studied above $800{ }^{\circ} \mathrm{C}$ in flowing $\mathrm{H}_{2}$ and $\mathrm{N}_{2}$ for pressures ranging from 10 to 700 torr. From careful weighings of the GaN film on sapphire before and after annealing, the rates for $\mathrm{GaN}$ decomposition, $\mathrm{Ga}$ surface accumulation, and $\mathrm{Ga}$ desorption were obtained. An enhancement in the $\mathrm{GaN}$ decomposition rate was observed in $\mathrm{H}_{2}$ pressures greater than 100 torr. Even with this enhanced GaN decomposition, the Ga desorption rate is nearly constant at higher pressures. As a result, Ga droplets accumulate on the surface. For $\mathrm{N}_{2}$ pressures ranging from 76 to 400 torr no net enhancement in the $\mathrm{GaN}$ decomposition rate is observed and the GaN decomposition rate is reduced compared to identical annealing conditions in $\mathrm{H}_{2}$. This suggests that $\mathrm{H}_{2}$ is acting chemically to reduce the barrier for $\mathrm{GaN}$ decomposition. This may occur through a surface mediated dissociation of $\mathrm{H}_{2}$ followed by the formation of more mobile and volatile hydrogenated $\mathrm{N}$ and $\mathrm{Ga}$ species. The significance of this study for $\mathrm{GaN}$ growth is that by increasing the $\mathrm{GaN}$ decomposition, the $\mathrm{Ga}$ atoms diffuse farther and subsequently reincorporate into the growing lattice, increasing the GaN crystal quality. Connections between the enhanced GaN decomposition rate and the coalescing of nucleation layer during the ramp to high temperature and the consequences for the high temperature growth are discussed.

\section{INTRODUCTION}

GaN is of current interest for the fabrication of blue light emitting diodes [1], lasers [2] and for high power electronic devices [3]. It has been shown that the $\mathrm{GaN}$ quality plays a strong role in the device performance [1-3]. Typically, GaN is grown at high temperature $\left(>1000{ }^{\circ} \mathrm{C}\right)$ using MOVPE with $\mathrm{N}$ to Ga ratios larger than 1000 on sapphire or SiC substrates using a thin buffer layer. The high temperature is necessary for efficient catalytic dissociation of $\mathrm{NH}_{3}$ and the large V/III ratio is needed to offset the $\mathrm{N}$ loss from the growing film [4]. The growth temperature is larger (i.e. $100-500{ }^{\circ} \mathrm{C}$ ) than the threshold temperature for $\mathrm{GaN}$ decomposition, and it is not currently understood to what extent $\mathrm{GaN}$ decomposes during growth at MOVPE pressures.

Previously, we suggested that decomposition of the GaN film during growth enhances $\mathrm{GaN}$ ordering, by eliminating more weakly incorporated $\mathrm{Ga}$ and $\mathrm{N}$ atoms [4]. At equilibrium the growth rate is zero. For a positive growth rate close to equilibrium, the incorporation rate of atoms into the growing lattice is slightly larger than the decomposition rate [4-6]. Recently, we showed how the $\mathrm{GaN}$ decomposition rate is enhanced in flowing $\mathrm{H}_{2}$ for pressures greater than 100 torr [7]. This result was explained by assuming chemical dissociation of $\mathrm{H}_{2}$ on the $\mathrm{GaN}$ surface which then increases Ga surface mobility and enhances $\mathrm{N}_{2}$ desorption. This paper reports a more detailed study of GaN decomposition in both $\mathrm{H}_{2}$ and $\mathrm{N}_{2}$ as a function of pressure and temperature, where the role of $\mathrm{H}_{2}$ on the enhanced $\mathrm{GaN}$ decomposition rate is clarified.

\section{EXPERIMENTAL DETAILS}

Details of the GaN growth are discussed elsewhere [8]. The GaN films were grown at 76 torr using a close-spaced showerhead reactor design. This same reactor was also used to study the GaN decomposition. The growth process resulted in specular GaN growth over the 2" sapphire wafer, with excellent thickness uniformity. Temperature reproducibility of the susceptor was a major concern for the decomposition study. The temperature was calibrated by observing the melting point of 0.005 " diameter Au wire and correlating it to a thermocouple in 

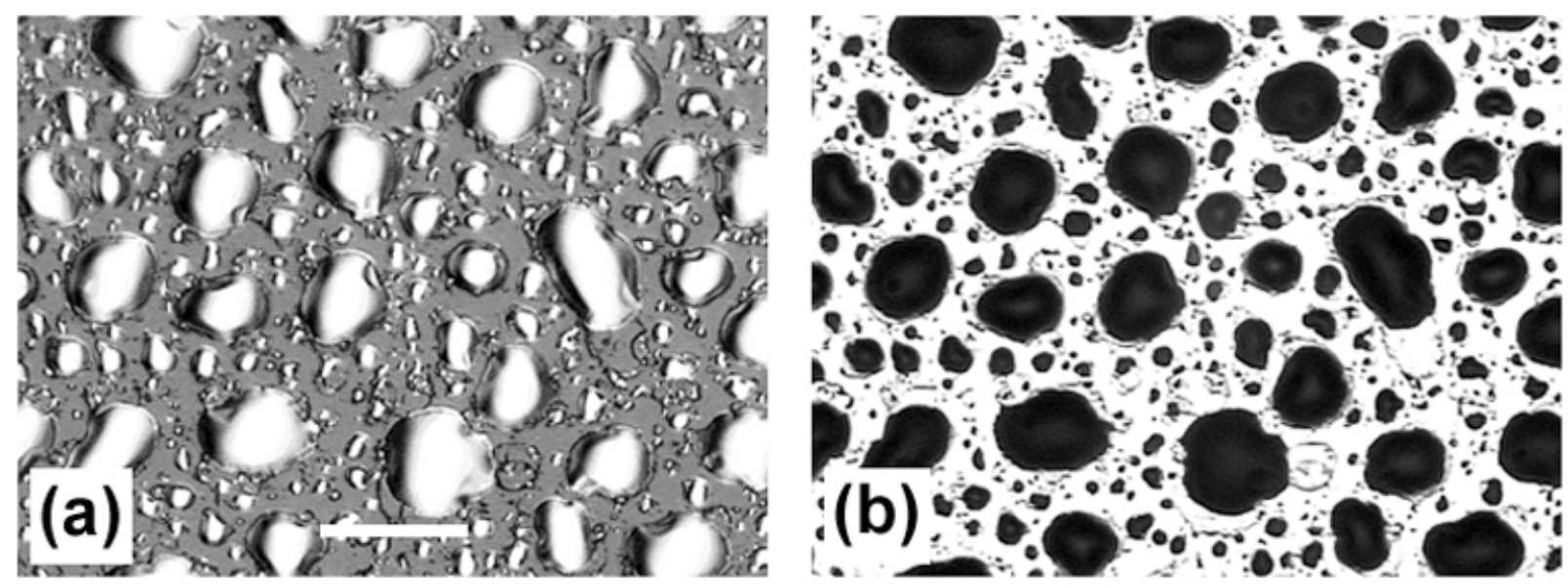

Figure 1. (a) Phase contrast and (b) transmission Normarski images of $\mathrm{GaN}$ surface heated for 20 minutes in $\mathrm{H}_{2}$ at a pressure of 150 torr at a temperature of $811^{\circ} \mathrm{C}$. The bar on image (a) indicates a length of $20 \mu \mathrm{m}$.

close proximity to with the backside of the susceptor. Temperature measurement in the reactor was found to be reproducible to within $5{ }^{\circ} \mathrm{C}$ after 8 months of use.

For the decomposition study, pieces of the GaN on sapphire were cleaved and weighed to within $0.1 \mathrm{mg}$ using an analytical balance [7]. Repeated weighing of the GaN on sapphire pieces were reproducible to within $0.1 \mathrm{mg}$. The pieces were reintroduced into the reactor and heated under varying conditions using either $6 \mathrm{SLM}$ flow of $\mathrm{H}_{2}$ or 3 SLM of $\mathrm{N}_{2}$. Each piece was ramped at $25{ }^{\circ} \mathrm{C}$ per minute to the annealing temperature, which ranged from 800 to $1130{ }^{\circ} \mathrm{C}$. After annealing for a set time and cooling, each piece was re-weighed in air to determine the mass loss. If $\mathrm{Ga}$ droplets were observed, they were removed by etching in dilute $\mathrm{HNO}_{3}$ and rinsing with DI water. (On some samples which were not etched, the Ga droplets were found to be very stable in air even up to several months, suggesting minimal oxidation of the liquid Ga droplets.) Each piece was then weighed again to determine the weight of liquid Ga. Finally, the piece was annealed at $1080{ }^{\circ} \mathrm{C}$ until the remaining $\mathrm{GaN}$ was decomposed, leaving only the initial bare sapphire surface. The bare sapphire weight was used to calculate the sapphire area in order to convert the measured weights to kinetic rates $\left(\right.$ atoms $\left./ \mathrm{cm}^{2}\right)$ [7].

\section{RESULTS}

After annealing $\mathrm{GaN}$ in the absence of $\mathrm{NH}_{3}$, the most notable change in the $\mathrm{GaN}$ surface morphology is the appearance of Ga droplets as shown in Fig. 1. For Fig. 1, the GaN surface was annealed at a temperature of $81{ }^{\circ} \mathrm{C}$ for 20 minutes in $\mathrm{H}_{2}$ at a pressure of 150 torr. The $\mathrm{Ga}$ droplets are observable as the lighter regions in the phase contrast image (Fig. 1(a)) and as the darker regions in the transmission image (Fig 1(b)). Because the GaN decomposition rate is larger than the Ga desorption rate, the liquid Ga droplets accumulate on the surface and coalesce into larger droplets, similar to the liquid droplet growth mechanism developed by Family and Meakin [9]. In flowing $\mathrm{H}_{2} \mathrm{Ga}$ droplets were observed for pressures greater than 22 torr [7] for anneals at $992{ }^{\circ} \mathrm{C}$. Compared to the $\mathrm{Ga}$ droplets in flowing $\mathrm{H}_{2}$, the $\mathrm{Ga}$ droplets in flowing $\mathrm{N}_{2}$ were barely discernable even at the highest magnification of 1000x. The droplet size increased as both the anneal temperature and the pressure were increased in $\mathrm{H}_{2}$ and in $\mathrm{N}_{2}$ for temperature greater than $1000{ }^{\circ} \mathrm{C}$.

For temperatures ranging from $800-1000{ }^{\circ} \mathrm{C}$, the $\mathrm{H}_{2}$ pressure had a strong influence on both the quantity of $\mathrm{Ga}$ and the Ga droplet size. This is shown in Fig. 2, where the kinetic rates for $\mathrm{Ga}$ accumulation (i.e. liquid $\mathrm{Ga}$ on the surface), $\mathrm{GaN}$ decomposition, and $\mathrm{Ga}$ desorption are plotted as a function of pressure. Figs. 2(a) through 2(c) show the rates at anneal temperatures of $992{ }^{\circ} \mathrm{C}, 902{ }^{\circ} \mathrm{C}$, and $811^{\circ} \mathrm{C}$, respectively. It is clear from Fig. 2(a) that the $\mathrm{GaN}$ decomposition rate (filled circles) and the surface Ga accumulation rate (open squares) increase as the pressure is increased. The $\mathrm{Ga}$ desorption rate (filled diamonds) changes slightly as a function of pressure, peaking near 76 torr in Fig. 2(a), 100 torr in Fig. 2(b), and 120 torr in Fig. 2(c). The increase in the Ga desorption rate at these pressures is due to a maximum in the Ga surface area to volume 

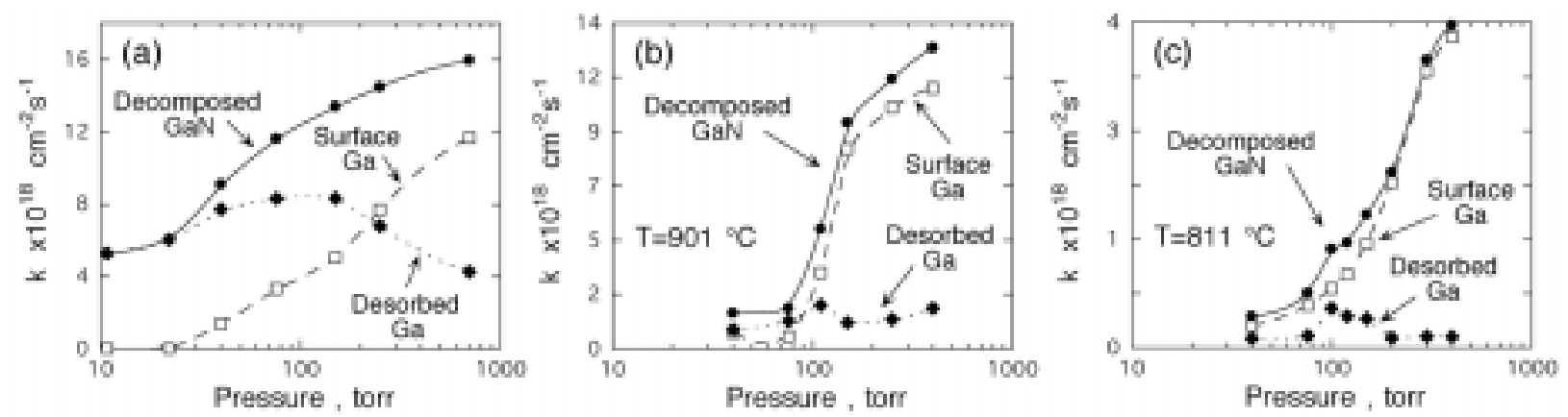

Figure 2. Plot of the $\mathrm{GaN}$ decomposition rate in $\mathrm{H}_{2}$ (solid circles) at various pressures at (a) $992{ }^{\circ} \mathrm{C}$, (b) $902{ }^{\circ} \mathrm{C}$, and (c) $811^{\circ} \mathrm{C}$. The Ga desorption rate (solid diamonds) and the rate of Ga accumulation (open squares) on the surface during the anneal are also plotted.

which then decreases as the droplets coalesce. Clearly, as shown in Fig 2(b) and 2(c), the buildup of $\mathrm{Ga}$ on the surface directly coincides with the increase in the $\mathrm{GaN}$ decomposition rate.

Arrhenius plots of the $\mathrm{GaN}$ decomposition and $\mathrm{Ga}$ desorption rates in both $\mathrm{H}_{2}$ and $\mathrm{N}_{2}$ are plotted in Figs. 3 and 4, respectively. Because the GaN decomposition rates depend strongly on the $\mathrm{H}_{2}$ pressure, the decomposition rates in $\mathrm{H}_{2}$ (solid circles, solid line) are plotted only for 76 torr. From this data, the fit yields a pre-exponential of $(6.3 \pm 0.4) \times 10^{30} \mathrm{~cm}^{-2} \mathrm{~s}^{-1}$ and an activation energy, $E_{\mathrm{A}}$, of $2.96 \pm 0.06 \mathrm{eV}$. This is in close agreement with previous measurements of $\mathrm{GaN}$ decomposition in vacuum, where pre-exponentials of $4 \times 10^{29} \mathrm{~cm}^{-2} \mathrm{~s}^{-1}$ [10] and $5 \times 10^{28} \mathrm{~cm}^{-2} \mathrm{~s}^{-1}$ [11] and an $\mathrm{E}_{\mathrm{A}}$ of $3.1 \mathrm{eV}[10,11]$ were measured. For comparison, values of the pre-exponentials and $\mathrm{E}_{\mathrm{A}}$ for the $\mathrm{GaN}$ decomposition and $\mathrm{Ga}$ desorption kinetics are listed in Table 1. Arrhenius plots of the $\mathrm{GaN}$ decomposition at higher $\mathrm{H}_{2}$ pressures gave slopes that were smaller than the slope measured at 76 torr, giving significantly smaller $E_{A}$ at higher pressures. These values for $E_{A}$ were not explicitly calculated because it is not clear if the GaN decomposition at these higher pressures is governed by a single, simple chemical mechanism. The GaN decomposition rates were also measured in $\mathrm{N}_{2}$ at pressures of 76 (open diamonds) and 150 torr (open squares). At fixed temperature in $\mathrm{N}_{2}$, the $\mathrm{GaN}$ decomposition rate was approximately constant for pressures up to 400 torr. In $\mathrm{N}_{2}$, an exponential fit gives a larger pre-exponential of $(1.2 \pm 0.1) \times 10^{32} \mathrm{~cm}^{-2} \mathrm{~s}^{-1}$ and an substantially larger $\mathrm{E}_{\mathrm{A}}$ of $3.62 \pm 0.04 \mathrm{eV}$ compared to the kinetic parameters measured in $\mathrm{H}_{2}$. The

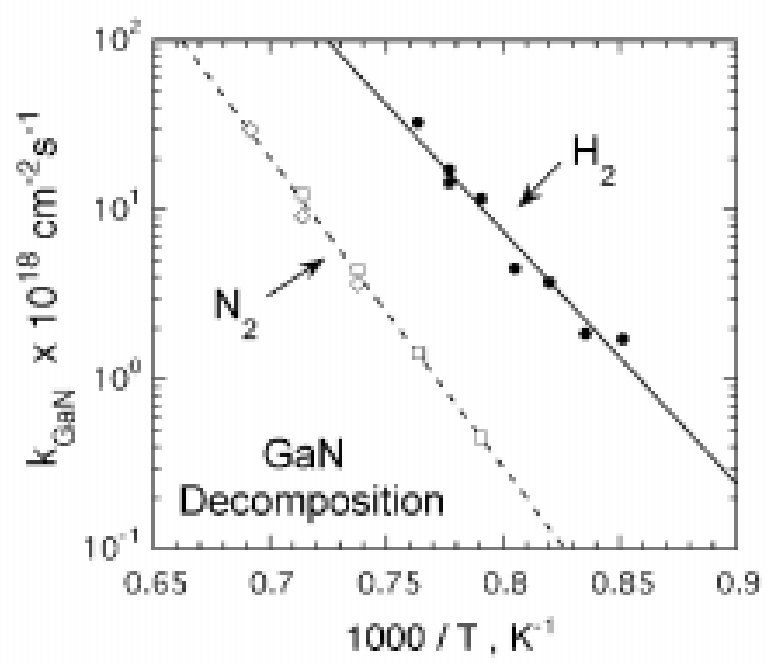

Figure 3. Arrhenius plot of the GaN decomposition rate vs. the reciprocal temperature under $\mathrm{H}_{2}$ (filled circles, solid line) and $\mathrm{N}_{2}$ (open diamonds and squares, dashed line). The pre-exponent and activation energy from the fit are listed in Table 1.

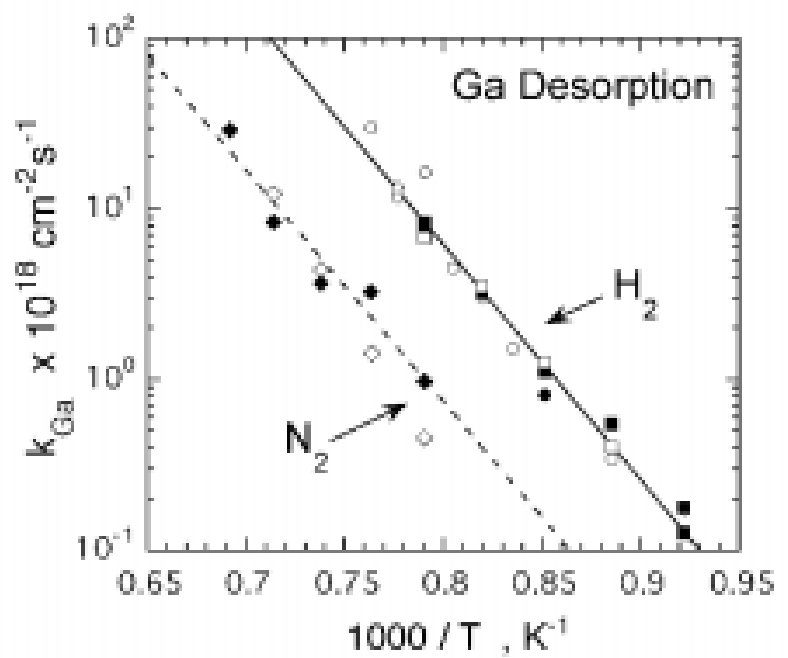

Figure 4. Arrhenius plot of the Ga desorption rate vs. the reciprocal temperature under $\mathrm{H}_{2}$ (filled and open circles and squares, solid line) and $\mathrm{N}_{2}$ (filled and open diamonds, dashed line). The pre-exponent and activation energy from the fit are listed in Table 1. 
TABLE I. Values for the kinetic parameters for GaN decomposition and Ga desorption. The first column lists the event, either GaN decomposition or Ga desorption and a brief description of the conditions for the study. The second column lists the measured pre-exponential and the third column lists the measured activation energy, $\mathrm{E}_{\mathrm{A}}$. The reference for the work listed in the table is shown in the fourth column.

\begin{tabular}{lccc}
\hline \hline \multicolumn{1}{c}{ Event } & pre-exponent & $\mathrm{E}_{\mathrm{A}}(\mathrm{eV})$ & Ref. \\
\hline GaN Decomposition & & & \\
\hline Thermogravimetry & $4 \times 10^{29} \mathrm{~cm}^{-2} \mathrm{~s}^{-1}$ & 3.1 & 10 \\
Mass Spectroscopy & $5 \times 10^{28} \mathrm{~cm}^{-2} \mathrm{~s}^{-1}$ & 3.1 & 11 \\
Mass Spectroscopy & $1.2 \times 10^{31} \mathrm{~cm}^{-2} \mathrm{~s}^{-1}$ & 3.93 & 12 \\
$\mathrm{H}_{2}$ at 76 torr & $(6.3 \pm 0.4) \times 10^{30} \mathrm{~cm}^{-2} \mathrm{~s}^{-1}$ & $2.96 \pm 0.06$ & this work \\
$\mathrm{N}_{2}$ at 76 and 150 torr & $(1.2 \pm 0.1) \times 10^{32} \mathrm{~cm}^{-2} \mathrm{~s}^{-1}$ & $3.62 \pm 0.04$ & this work \\
Ga Desorption & & & \\
desorption from liquid Ga & - & 2.8 & 14 \\
RHEED study & $1.0 \times 10^{28} \mathrm{~cm}^{-2} \mathrm{~s}^{-1}$ & 2.69 & 15 \\
$\mathrm{H}_{2}$ at 40, 76, 150, 250 torr & $(6.6 \pm 0.5) \times 10^{29} \mathrm{~cm}^{-2} \mathrm{~s}^{-1}$ & $2.74 \pm 0.06$ & this work \\
$\mathrm{N}_{2}$ at 76 and 150 torr & $(5.3 \pm 0.4) \times 10^{28} \mathrm{~cm}^{-2} \mathrm{~s}^{-1}$ & $2.69 \pm 0.08$ & this work \\
\hline
\end{tabular}

$\mathrm{GaN}$ decomposition kinetic parameters measured in $\mathrm{N}_{2}$ are closer to the mass spectroscopy work of Ambacher and coworkers [12] as shown in Table I.

$\mathrm{GaN}$ decomposition was also studied as a function of time at a fixed pressure of 150 torr and temperature of $811^{\circ} \mathrm{C}$. Images of the surface after (a) 3, (b) 10, (c) 20, and (d) 80 minutes are shown in Fig. 5. As shown in Fig. 5, the average Ga droplet size increases as the surface is annealed as described by the model of Family and Meakin [9]. After an initial incubation time, the $\mathrm{GaN}$ decomposition rate, $\mathrm{Ga}$ surface accumulation rate, and the $\mathrm{Ga}$ desorption rate were relatively constant in time suggesting zeroth order kinetics. Also, for one experiment the GaN surface was predosed with trimethylgallium for 10 minutes at $600{ }^{\circ} \mathrm{C}$ prior to the high temperature anneal in $\mathrm{H}_{2}$. In agreement with the work of Pisch and Schmid-Fetzer who observed enhanced $\mathrm{GaN}$ decomposition on $\mathrm{Ga}$ predosed surfaces [13], a 34\% increase in the GaN decomposition rate was observed on the Ga predosed surface. While the increase in the GaN decomposition rate by $\mathrm{Ga}$ predosing the surface is significant, it is not as large as the increase observed in Fig. 2 when the $\mathrm{H}_{2}$ pressure is increased from low ( $<76$ torr) to high pressure $(>150$ torr). From this work it is apparent that the GaN decomposition rates depend strongly on the ambient gas (i.e. $\mathrm{H}_{2}$ or $\mathrm{N}_{2}$ ), the pressure, and the condition of the initial surface.

Contrary to the large range in the measured kinetic parameters for $\mathrm{GaN}$ decomposition, the measured $\mathrm{E}_{\mathrm{A}}$ for $\mathrm{Ga}$ desorption were found to be both independent of pressure and ambient gas composition. The data shown in Fig. 4 for $\mathrm{H}_{2}$ were measured at 40 (solid circles), 76 (open circles), 150 (solid squares), and 250 (open squares) torr. From a fit to all the data a preexponential of $(6.6 \pm 0.5) \times 10^{29} \mathrm{~cm}^{-2} \mathrm{~s}^{-1}$ and an $\mathrm{E}_{\mathrm{A}}$ of $2.74 \pm 0.06 \mathrm{eV}$ were measured [7]. In $\mathrm{N}_{2}$, the desorption rates were measured at 76 (solid diamonds) and 150 (open diamonds) torr, yielding a pre-exponential of $(5.3 \pm 0.4) \times 10^{28} \mathrm{~cm}^{-2} \mathrm{~s}^{-1}$ and an $\mathrm{E}_{\mathrm{A}}$ of $2.69 \pm 0.08 \mathrm{eV}$. Both measurements of the
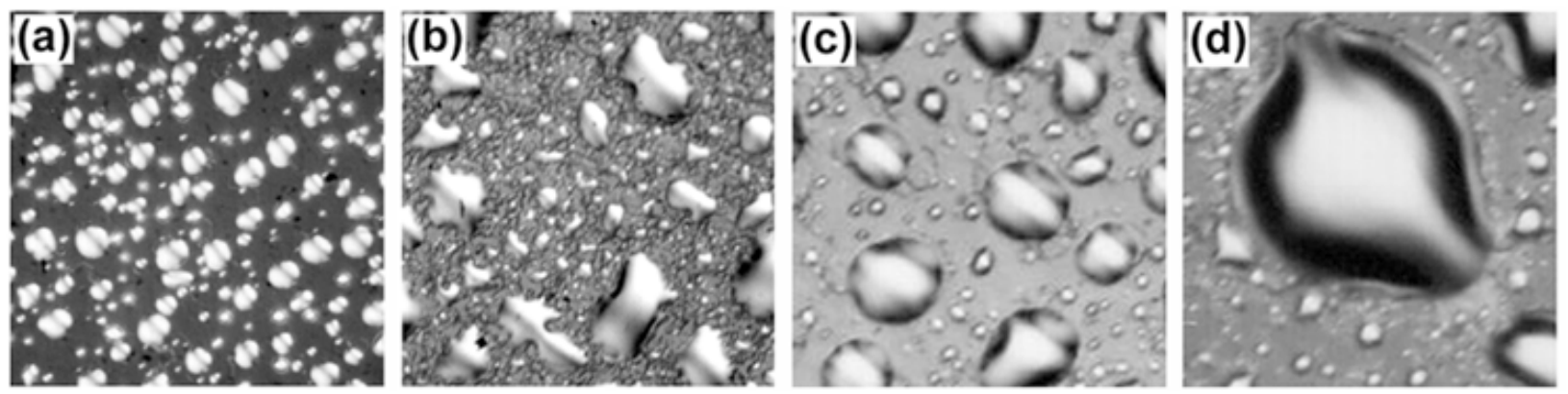

Figure 5: The growth in the Ga droplet size is shown for GaN surfaces anneal at $811{ }^{\circ} \mathrm{C}$ for (a) 3, (b) 10 , (c) 20 , and (d) 80 minutes in $\mathrm{H}_{2}$ at a pressure of 150 torr. 
$\mathrm{Ga}$ desorption $\mathrm{E}_{\mathrm{A}}$ are in excellent agreement with the value of $2.8 \mathrm{eV}$ for Ga desorption from liquid $\mathrm{Ga}$ [14], and $2.69 \mathrm{eV}$ for $\mathrm{Ga}$ desorption from $\mathrm{GaN}$ in vacuum [15]. The preexponential measured in $\mathrm{H}_{2}$ is 12.5 larger than in $\mathrm{N}_{2}$, which is close to the mass ratio of $\mathrm{N}_{2}$ to $\mathrm{H}_{2}$ of 14. The mechanism for $\mathrm{Ga}$ desorption suppression in $\mathrm{N}_{2}$ and implications for $\mathrm{GaN}$ growth will be discussed in the next section.

\section{DISCUSSION AND CONCLUSIONS}

$\mathrm{GaN}$ thermal decomposition has been extensively studied in vacuum [10-12, 16-19]. From these previous studies activation energies, $\mathrm{E}_{\mathrm{A}}$, of $3.1 \mathrm{eV}[10,11]$ and $3.93 \mathrm{eV}$ [12] were measured as listed in Table 1. In this study, we have shown how the measured kinetic parameters vary depending on the pressure and ambient gas. For example, in $\mathrm{N}_{2}$ a larger $\mathrm{E}_{\mathrm{A}}(3.62 \mathrm{eV})$ is measured compared to a lower $\mathrm{E}_{\mathrm{A}}(2.96 \mathrm{eV})$ measured in $\mathrm{H}_{2}$ at 76 torr. The $\mathrm{E}_{\mathrm{A}}$ are even lower in $\mathrm{H}_{2}$ when the pressure is increased above 100 torr. These differences in the $\mathrm{E}_{\mathrm{A}}$ reflect a change in the $\mathrm{GaN}$ decomposition mechanism when $\mathrm{GaN}$ is heated in $\mathrm{H}_{2}$ vs. heating in $\mathrm{N}_{2}$.

The decomposition rate enhancement at high pressure coincides with an increase in liquid Ga coverage. Recently, Pisch and Schmid-Fetzer showed that liquid Ga can catalyze GaN decomposition for temperatures as low as $720^{\circ} \mathrm{C}$ [13]. Although Ga droplet formation coincides with an increase in the GaN decomposition rate, it is not known if the liquid $\mathrm{Ga}$ accumulation is the cause or a result of the increased GaN decomposition rate. In Fig. 2, we show that the GaN decomposition rate is enhanced at higher pressure in $\mathrm{H}_{2}$. However, no enhancement is observed in $\mathrm{N}_{2}$. This implies that the GaN surface is chemically altered in $\mathrm{H}_{2}$ and that $\mathrm{N}$ is preferentially removed from the lattice while the Ga desorption rate remains relatively constant.

To preferentially remove $\mathrm{N}$ from the lattice, the $\mathrm{H}_{2}$ must first dissociate and adsorb on the surface. Ga metal is known to dissociate $\mathrm{H}_{2}$ at high temperatures to form $\mathrm{Ga}$ hydrides [20]. The hydrogenated $\mathrm{N}$ and Ga species have the potential to be both more mobile and also more volatile. More mobile hydrogenated $\mathrm{Ga}$ species have been proposed to explain the increase in the $\mathrm{Ga}$ diffusion length when $\mathrm{H}_{2}$ or atomic $\mathrm{H}$ is used in the MBE growth of GaAs [21]. In addition, Okamoto and coworkers have recently showed a suppression of 3D growth morphology when atomic $\mathrm{H}$ is used during MBE growth of $\mathrm{GaN}$ [22], implying an increase in the surface mobility for the hydrogenated $\mathrm{Ga}$ atoms. Increasing the $\mathrm{Ga}$ diffusion length would more rapidly uncover new areas of the $\mathrm{GaN}$ surface for $\mathrm{N}_{2}$ desorption, which is $10-10^{4}$ times faster than the $\mathrm{Ga}$ desorption rate for the temperature range of $800-1100{ }^{\circ} \mathrm{C}[4,15]$. Furthermore, the surface $\mathrm{H}$ can form more volatile $\mathrm{NH}_{\mathrm{x}}$ species. Both an increased rate of $\mathrm{NH}_{\mathrm{x}}$ desorption and an increased $\mathrm{GaH}$ mobility, will lead to the formation and growth of Ga droplets as shown in Figs. 1 and 5. When $\mathrm{N}_{2}$ is substituted for $\mathrm{H}_{2}$, the $\mathrm{E}_{\mathrm{A}}$ for decomposition is larger because the chemical pathways for forming hydrogenated $\mathrm{N}$ and $\mathrm{Ga}$ species are absent. In $\mathrm{N}_{2}$, the kinetic barrier to $\mathrm{GaN}$ decomposition is larger and may be limited by the formation and desorption rate of $\mathrm{N}_{2}$.

Compared to the $\mathrm{GaN}$ decomposition kinetics, $\mathrm{Ga}$ desorption is simpler. The $\mathrm{E}_{\mathrm{A}}$ listed in Table 1 all are in the range 2.69-2.8 eV, implying that the $\mathrm{Ga}$ desorption mechanism is similar under varying pressures and ambient gas flows. The agreement in the $\mathrm{E}_{\mathrm{A}}$ for Ga desorption from liquid $\mathrm{Ga}[14]$ and the similarity of the measured $\mathrm{E}_{\mathrm{A}}$ values in Table 1, suggest that the Ga atoms desorb from a Ga rich surface. As shown in Fig. 4, the measured pre-exponential factor in $\mathrm{H}_{2}$ is 12.5 times the measured pre-exponential factor in $\mathrm{N}_{2}$, which is close to the mass difference of 14 between $\mathrm{N}_{2}$ and $\mathrm{H}_{2}$. With the $\mathrm{N}_{2}$ and $\mathrm{H}_{2}$ molecules initially near room temperature $\left(2{ }^{\circ} \mathrm{C}\right)$, their impact with the hot surface (near $800-1050{ }^{\circ} \mathrm{C}$ ) would likely result in a general heat removal from the surface. The heat transfer between the $\mathrm{N}_{2}$ and the hot surface is more efficient than between $\mathrm{H}_{2}$ and the surface, because of its larger mass (more impulsive collision) and slower speed (mean speed of $\mathrm{N}_{2}$ is 3.7 times slower than $\mathrm{H}_{2}$ ) its collision time with the surface is longer. As a result of the increased collision time, heat transfer from the hotter surface $\mathrm{Ga}$ atoms to the cooler $\mathrm{N}_{2}$ molecules is more efficient, resulting in a reduced population density of the Ga surface vibrations which lead to $\mathrm{Ga}$ desorption. The net effect of this is a reduction in attempt frequency (i.e. preexponential factor) for Ga desorption in $\mathrm{N}_{2}$ compared to $\mathrm{H}_{2}$.

This study of GaN decomposition has several consequences for the growth of GaN. We have found that the material quality is substantially improved when $\mathrm{GaN}$ growth is conducted above 100 torr. When the GaN epitaxial layer is grown above 100 torr, we find a near doubling of the electronic mobility $\left(\mu>500 \mathrm{~cm}^{2} / \mathrm{Vs}\right.$ for intentionally Si doped films with $\left.\mathrm{n}=2-3 \times 10^{17} \mathrm{~cm}^{-3}\right)$

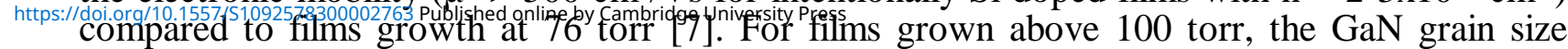


increased from $<1 \mu \mathrm{m}$ to $2-5 \mu \mathrm{m}$, which may be directly responsible for the increased mobility [23]. Other groups using close-spaced or high speed rotating disk reactors have also reported improved electric properties when the pressure of the $\mathrm{GaN}$ growth is greater than 100 torr [24, 25]. Larger grains and narrower x-ray rocking curve widths have been reported for the growth of unnucleated $\mathrm{GaN}$ on sapphire in $\mathrm{H}_{2}$ compared to $\mathrm{N}_{2}$ [26], suggesting that the enhanced decomposition in $\mathrm{H}_{2}$ aids in the breakup of smaller grains. Changes in the nucleation layer evolution during the ramp from low to high temperature have also been observed as a function of $\mathrm{H}_{2}$ pressure [25, 27]. Enhanced $\mathrm{GaN}$ decomposition in $\mathrm{H}_{2}$ may also increase the size and aid in the coalescence of the low temperature nucleation layers as shown by Han et al. [25]. If insufficient $\mathrm{NH}_{3}$ is supplied, the GaN nucleation layer may be entirely decomposed [28], especially if the nucleation layer is annealed under higher $\mathrm{H}_{2}$ pressure.

This study illustrates the significant differences between reduced and atmospheric pressure MOVPE GaN growth and the influence of carrier gas chemistry. We have demonstrated the direct influence of $\mathrm{H}_{2}$ pressure on the $\mathrm{GaN}$ decomposition rate. A more thorough understanding of the GaN decomposition mechanism at the higher growth pressures currently used by many groups may serve to clarify the mechanisms contributing to GaN growth.

\section{ACKNOWLEDGEMENTS}

We thank JA Freitas, Jr. and W.J. Moore for characterization of films. This work is supported by the Office of Naval Research and the ONR Power Electronic Building Block Program (PEBB) monitored by George Campisi.

\section{REFERENCES}

[1] S. Nakamura, M. Senoh, and T. Mukai, Appl. Phys. Lett. 64,1687 (1994).

[2] S. Nakamura, M. Senoh, S. Nagahama, N, Iwasa, T. Yamada, T. Matsushita, H, Kiyoku, Y. Sugimoto, Jpn. J. Appl. Phys. 35, L74 (1996).

[3] S.N. Mohammad, A.A. Salvador, and H. Morkoc, Proc. IEEE 83, 1306 (1995); S. Strite and H. Morkoc, J. Vac. Sci. Technol. B 10, 1237 (1992); R.F. Davis, Proc. IEEE 79, 702 (1991).

[4] D.D. Koleske, A.E. Wickenden, R.L. Henry, W.J. DeSisto, and R.J. Gorman, J. Appl. Phys. 84, 1998 (1998).

[5] S.Yu. Karpov and M.A. Maiorov, Surf. Sci. 393, 108 (1997).

[6] R. Heckingbottom in Molecular Beam Epitaxy and Heterostructures, eds. L.L. Chang and K. Ploog, (Martinus Nijhoff, Dordrecht, 1985). p. 71.

[7] D.D. Koleske, A.E. Wickenden, R.L. Henry, M.E. Twigg, J.C. Culbertson, and R.J. Gorman, Appl. Phys. Lett. 73, 2018 (1998).

[8]. M. Fatemi, A.E. Wickenden, D.D. Koleske, M.E. Twigg, J.A. Freitas, Jr., R.L. Henry, and R.J. Gorman, Appl. Phys. Lett. 73, 608 (1998).

[9]. F. Family and P. Meakin, Phys. Rev. Lett. 61, 428 (1988).

[10]. Z.A. Munir and A.W. Searcy, J. Chem. Phys. 42, 4223 (1965).

[11]. R. Groh, G. Gerey, L. Bartha, and J.I. Pankove, Phys. Stat. Sol. A 26, 353 (1974).

[12] O. Ambacher, M.S. Brandt, R. Dimitrov, T. Metzger, M. Stutzmann, R.A. Fischer, A. Miehr, A. Bergmaier, and G. Dollinger, J. Vac. Sci. Technol. B 14, 3532 (1996).

[13] A. Pisch and R. Schmid-Fetzer, J. Cryst. Growth 187, 329 (1998).

[14]. R.E. Honig and D.A. Kramer, RCA Rev. 30 , 285 (1969).

[15] O. Brandt, H. Yang, and K.H. Ploog, Phys. Rev. B 54, 4432 (1996).

[16] W.C. Johnson, J.B. Parsons, and M.C. Crew, J. Phys. Chem. 36, 2651 (1932).

[17] R.J. Sime and J.L. Margrave, J. Phys. Chem. 60, 810 (1956).

[18] R.C. Schoonmaker, A. Buhl, and J. Lemley, J. Phys. Chem. 69, 3455 (1965).

[19] A.S. Bolgar, S.P. Gordienko, E.A. Ryklis, and V.V. Fesenko, in: Chemistry and Physics of the Nitrides (ed. by G.V. Samsonov) [in Russian], (Naukova, Dumka, Kiev 1968), p. 151; also see I.G. Pichugin and D.A. Yas'kov, Izvestiya Akademii Nauk SSSR, Neorganicheskie Materialy 6, 1973 (1970).

[20] H. Remy, Treatise on Inorganic Chemistry, (Elsevier, New York, 1960), p. 18; W.R.S. Garton, Proc. Phys.

Soc. A 64, 509 (1951).

[21] Y. Morishita, Y. Nomura, S. Goto, and Y. Katayama, Appl. Phys. Lett. 67, 2500 (1995).

[22] Y. Okamoto, S. Hashiguchi, Y. Okada, and M. Kawabe, Jpn. J. Appl. Phys. 37, L1109 (1998).

[23]. S.D. Hersee, J.C. Ramer, and K.J. Malloy, MRS Bulletin 22, 45 (1997). 
[24] B.T. McDermott, R. Pittman, E.R. Gertner, J. Krueger, C. Kisielowski, Z. Lilienthal-Weber, and E. Weber, Talk D2.2 at Fall Material Research Society Meeting, Boston, 1997.

[25] J. Han, and T.-B. Ng, R.M. Biefeld, M.H. Crawford, D.M. Follstaedt, Appl. Phys. Lett. 71, 3114 (1997).

[26] T.J. Kistenmacher, D.K. Wickenden, M.E. Hawley, and R.P. Leavitt, Mat. Res. Soc. Symp. Proc. 395, 261 (1996).

[27] J.C. Ramer, K. Zheng, C.F. Kranenberg, M. Banas, and S.D. Hersee, Mat. Res. Soc. Symp. Proc. 395,225 (1996).

[28] Y. Kobayashi, T. Akasaka, and N. Kobayashi, Jpn. J. Appl. Phys. 37, L1208 (1998). 